\title{
Amsterdaml'og \\ MeProRisk - New methodology for the development of geothermal reservoirs
}

\author{
J. Arnold ${ }^{1}$, R. Pechnig, D. Mottaghy
}

MeProRisk is a joint project of five university institutes at RWTH Aachen University, Free University Berlin, and Kiel University. Two partners, namely Geophysica Beratunggesellschaft mbH (Aachen) and RWE Dea AG (Hamburg) present the industrial side. It is funded by the German Ministry of Education and Science (BMBF).

The focus is set on the development of a novel integrated procedure to explore geothermal reservoirs in order to minimize the risk at their exploitation. Our studies are related to three different type locations in Germany. These are (1) the crystalline basement in South Germany, (2) the Rotliegend formation and volcanic rocks in the Northern German Sedimentary Basin and (3) Paleozoic rocks beneath the sedimentary subsurface in the Northern Germany Basin.

In our part of the project we acquire geothermal relevant basis data from core and borehole measurements. This data will be integrated with seismic measurements which are observed over a wider area. From the information on different scales we derive specific values for each rock type with respect to geothermal relevant parameters. These are porosity, permeability, density, thermal conductivity and $p$-wave velocity, for example. Finally these basis data exhibit the input parameter to calculate a 3D reservoir model.

Meanwhile we worked on two type locations:

In the case of the crystalline basement an extensive dataset could be composed from the $9 \mathrm{~km}$ deep KTB borehole including logging, core and cutting data. The whole data could be interpreted with respect to lithology, structure and alteration of the formation which mainly consists of alternating sequences of gneiss and metabasite. For the different rock types the data was analyzed statistically to provide specific values for geothermal key parameters.

For the second type location we used logging data recovered within one borehole ( $>5 \mathrm{~km}$ deep) which was drilled in the so called Voelkersen gas field. The data was supplied by the RWE DEA company. The formation comprises volcanic rocks and sandstones. On corresponding cores we measured p-wave velocity, thermal conductivity, density and porosity in our laboratory. In the same way as for type location (1) the complete data set was analyzed statistically to derive specific values which are relevant for the geothermal reservoir model.

In a further step special computer software has to be developed which enables the multi-scale implementation of the well and its direct environment in a 3D reservoir model.

${ }^{1}$ Geophysica GmbH, Lütticher Str. 32, D-52064 Aachen, info@geophysica.de / Phone: +4924118992915 